\title{
A prospective study of maternal and fetal outcome in repeat LSCS mother
}

\author{
Pradeep Ganiga, Shanthala Rudrappa*
}

Department of Obstetrics and Gynecology, A. J. Institute of Medical Sciences, Mangalore, Karnataka, India

Received: 12 February 2019

Accepted: 22 February 2019

\section{*Correspondence:}

Dr. Shanthala Rudrappa,

E-mail: shanthalar18@gmail.com

Copyright: () the author(s), publisher and licensee Medip Academy. This is an open-access article distributed under the terms of the Creative Commons Attribution Non-Commercial License, which permits unrestricted non-commercial use, distribution, and reproduction in any medium, provided the original work is properly cited.

\begin{abstract}
Background: Cesarean section is one of the most commonly performed abdominal operations on women in most countries. The incidence of primary LSCS is increasing all over the world, Consequently, there is a rise in multiple repeat LSCS with associated complications. Previous LSCS is a common indication for repeat LSCS. Primarily, authors aim at studying the influence of repeat LSCS on maternal and fetal outcome in a tertiary centre.

Methods: All mothers with one previous LSCS admitted for emergency/elective LSCS at term gestation with singleton pregnancy in A.J. Institute of Medical Sciences and Research centre, Mangalore were recruited in the study from July to December 2018. Detailed history with antenatal risk factors were noted. Intraoperative and postoperative events were noted. Neonatal outcome was also noted correlated.

Results: Majority of patients (58\%) were in age group of 20-24years. Most of them were between 38 to 39 weeks of gestation. Most common intraoperative complication was bladder adhesion (18\% of cases). In postoperative period febrile morbidity (7\%) was common followed by urinary tract infection (2\%). Most of the neonates $(80 \%)$ weighed 2.5 to $3 \mathrm{~kg}$ at birth. The incidence of poor APGAR respiratory distress, NICU admission was not significantly increased. There were 5 morbidly adherent placenta, 1 scar rupture, 4 scar dehiscence, no maternal or perinatal death.

Conclusions: Previous caesarean is the most common cause of repeat caesarean and is associated with maternal morbidity. Measures should be taken to reduce primary caesarean sections which indirectly reduces the incidence of repeat cesarean sections.
\end{abstract}

Keywords: Maternal fetal outcome, Repeat cesarean, Repeat LSCS

\section{INTRODUCTION}

Cesarean section is one of the most commonly performed abdominal operations on women in most countries. The incidence of primary LSCS is increasing all over the world, Consequently, there is a rise in multiple repeat LSCS's with associated complications. Previous LSCS is a common indication for repeat LSCS in either emergency or elective cases. Many studies have been come to encourage VBAC to reduce maternal morbidity and mortality due to previous LSCS, but overall trend is not encouraging due to association with maternal complications like scar dehiscence, scar rupture and other conditions. ${ }^{1}$ Due to the fear of uterine rupture during trial of labor, repeat LSCS is being performed by many obstetricians. Repeat LSCS also contributes to the increasing LSCS rate. $^{2}$

Repeat multiple LSCS are associated with an increase in the risk of placenta praevia with other operative complications such as abdominal wall adhesions, bladder and bowel adhesions and injuries, ureteric injuries, haemorrhage, uterine dehiscence and rupture of the uterus. $^{3}$ Postoperative complications are wound infections, thromboembolism, endometritis, urinary tract infection, fever and blood transfusions. ${ }^{4}$ Primarily, 
authors aim at studying the influence of repeat LSCS on maternal and fetal outcome in a tertiary centre and also study the influence of repeat LSCS on intraoperative events like intraperitoneal adhesions, condition of the bladder and lower uterine segment, extension of uterine incisions, placenta previa, postpartum haemorrhage (PPH), blood transfusion and postoperative morbidity.

An outcome of secondary interest is the influence of timing of the LSCS (elective or emergency) on maternal outcome as regards the condition of the lower segment, uterine dehiscence and rupture, as well as neonatal complications.

\section{METHODS}

Data from 100 mothers with singleton pregnancy, term gestation with one previous LSCS who underwent elective/emergency LSCS in A. J. Institute of Medical Sciences and Research centre shall be recruited into the study from July 2018 to December 2018 was collected. Detailed history was taken from all repeat LSCS mothers with the inclusive criteria who consented to participate in this study.

\section{Maternal outcome measured were:}

- Antenatal period risk factors

- Intraoperative events bowel adhesion, bladder adhesion, atonic uterus

- Postoperative events like when the bowel sound was heard, catheter removal day, suture removal day, and postoperative complications such as wound infection, sepsis, fever.

Neonatal outcome such as caput present or absent, birth weight, APGAR at one and five minutes and admission to NICU

All the data collected were compiled and correlated.

\section{Inclusion criteria}

- $\quad$ Singleton pregnancy

- Term gestation

- With h/o one previous LSCS

- Patients not undergone any gynecological surgery.

\section{Exclusion criteria}

- Preterm gestation

- Multiple gestation

- More than 1 previous LSCS

- H/o previous gynecological surgeries

- Inter delivery interval $<18$ months.

\section{Statistical analysis}

Sample size was calculated using the formula: $\mathrm{n}=\mathrm{z}^{2} \mathrm{P}(1-\mathrm{P}) 1 \mathrm{~d}^{2}$
$\mathrm{n}$ - sample size
$\mathrm{Z}$ - statistics for a level of confidence
$\mathrm{P}$ - expected prevalence or proportion
d - precision.

\section{RESULTS}

Antenatal women with inclusion criteria who underwent repeat cesarean section in AJ Institute of Medical sciences from July 2018 to December 2018 were included in the study.

A total number of 100 patients were included in present study. Age, gestational age and antenatal risk factors were noted and tabulated.

Among 100 women with previous cesarean section, majority $(56 \%)$ were in age group of 25-29years. This was followed by $20-24$ years of age group (34\%). Lastly $6 \%$ were above $35 y$ years and $3 \%$ were of $<20$ years age (Table 1).

Table 1: Details of age distribution among the participants in percentage.

\begin{tabular}{|l|l|}
\hline Age of the participants (years) & Percentage \\
\hline$<20$ & 3 \\
\hline $20-24$ & 34 \\
\hline $25-29$ & 56 \\
\hline $30-34$ & 11 \\
\hline$>35$ & 6 \\
\hline
\end{tabular}

Gestational age was $38-38$ weeks 6 days in $74 \%$ of cases during which time either elective or emergency cesarean section was done. $18 \%$ were between 38 weeks to 38 weeks 6 days. There was no one above 40 weeks of gestation in present study, while $6 \%$ women were of $<37$ weeks of gestation. Hence observed that elective cesarean section is most commonly done 2 weeks prior to the expected date of delivery (Table 2).

Table 2: Distribution of gestational age among the participants, $\mathrm{N}=\mathbf{1 0 0}$.

\begin{tabular}{|l|l|}
\hline Gestational age in weeks & $\%$ of participants \\
\hline$<37$ weeks & 6 \\
\hline 37 weeks to 37 weeks 6 days & 74 \\
\hline 38 weeks to 38 weeks 6 days & 18 \\
\hline 39 weeks to 39 weeks 6 days & 2 \\
\hline$>40$ weeks & 0 \\
\hline
\end{tabular}

Anemia is the most common complication in Indian population. As it was observed in present study that the most common antenatal complication among antenatal women was anaemia (22\%). Also, cesarean section has more blood loss compared to vaginal delivery, thus adding to more prevalence of anemia. Second most common antenatal complication was hypertensive disease of pregnancy which was $8 \%$ of total study group. Others 
were gestational diabetes $(4 \%)$, heart disease $(2 \%)$. (Table 3).

Table 3: Distribution of antenatal risk factors, $\mathrm{N}=36$.

\begin{tabular}{|l|l|}
\hline Antenatal risk factor & Percentage \\
\hline Anaemia & 22 \\
\hline Hypertensive disease in pregnancy & 8 \\
\hline Gestational diabetes & 4 \\
\hline Heart disease & 2 \\
\hline
\end{tabular}

Intraoperative complications were assessed and tabulated accordingly. Bladder adhesion was the most common complication observed which was seen in $18 \%$ cases. This was managed by sharp and blunt dissections to push the bladder down. Bowel adhesions to uterus and anterior abdominal wall was observed in $6 \%$ cases. Atonic uterus requiring blood transfusion was observed in $11 \%$ cases. There were 5 cases of morbidly adherent placenta, 1 scar rupture, 4 scar dehiscence (Table 4). No maternal death due to complications was noted during present study period.

Table 4: Incidence of intra-operative complications, $\mathrm{N}=45$.

\begin{tabular}{|l|l|}
\hline Intra-operative complications & $\%$ \\
\hline Bladder adhesions & 18 \\
\hline Bowel adhesions & 6 \\
\hline Atonic uterus & 11 \\
\hline Morbidly adherent placenta & 5 \\
\hline Scar rupture & 1 \\
\hline Scar dehiscence & 4 \\
\hline
\end{tabular}

Postoperative complications assessed included day of bowel sounds heard, catheter removal day, suture removal day, febrile illness, urinary tract infection. Bowel sounds was heard in majority of patients within 6hrs of cesarean section $(68 \%)$. 20\% had bowel sounds heard between $6 \mathrm{hrs}$ to $12 \mathrm{hrs}$ post-surgery. Only $12 \%$ patients had bowel sounds heard after 24hrs (Table 5).

Table 5: Distribution of patients based on bowel sounds heard after cesarean section.

\begin{tabular}{|l|l|}
\hline Bowel sounds heard & $\%$ \\
\hline$<6$ hours & 68 \\
\hline $6-12$ hours & 20 \\
\hline$>12$ hours & 12 \\
\hline
\end{tabular}

Table 6: Distribution of patients based on urinary catheter removal day after cesarean section.

\begin{tabular}{|l|l|}
\hline Urinary catheter removal day & $\%$ \\
\hline$<3$ days & 78 \\
\hline$>3$ days & 22 \\
\hline
\end{tabular}

In $78 \%$ patient's urinary catheter was removed within 3 days. $22 \%$ of patients had catheter removed after 3 days, the main reason being dense bladder adhesions due to previous cesarean sections (Table 6).

Wound infection was seen in $18 \%$ cases, managed with secondary suturing or daily dressing (Table 7). Unexplained fever was seen in $7 \%$ cases, managed with broad spectrum antibiotics.

Table 7: Incidence of sepsis.

\begin{tabular}{|l|l|}
\hline Sepsis & Incidence \\
\hline Wound infection & $18 \%$ \\
\hline Unexplained fever & $7 \%$ \\
\hline
\end{tabular}

Neonatal outcome like birthweight, NICU admissions, mortality were assessed. $62 \%$ of babies were within 2.5 to $3.5 \mathrm{~kg}, 18 \%$ were $>3.5 \mathrm{~kg}$ and $20 \%$ neonates were $<2.5 \mathrm{~kg}$ (Table 8). NICU admissions were seen in $28 \%$ cases, most common reason being respiratory distress. Authors observed no neonatal morbidity in present study.

Table 8: Distribution of neonatal birthweight among study population.

\begin{tabular}{|l|l|}
\hline Birth weight in kgs & $\%$ \\
\hline 2.5 to 3.5 & 62 \\
\hline$>3.5$ & 18 \\
\hline$<2.5$ & 20 \\
\hline
\end{tabular}

\section{DISCUSSION}

There has been a significant increase in the CS rate worldwide, despite variations according to a patient age, place of residence, and cultural conditions. This increase is especially evident for women in cities and those over the age of $35 .^{5}$ Repeated cesarean birth is related to serious maternal and fetal complications when compared to normal birth and the first cesarean. ${ }^{6}$ However, medicolegal factors, increased reliability of cesarean birth, and decreased rates of vaginal birth after CS play important roles in the current increased CS rates. Another serious problem is the higher cost of CS, especially in developed countries. ${ }^{7}$ Adhesions are a cause of acute morbidity with bleeding and increased surgery duration and of chronic morbidity with chronic pelvic pain and intestinal problems. An increasing number of CSs increases the adhesion rate as well as intensity.,8 In addition, the adhesions can cause additional increased morbidity directly or with peripheral organ injury. ${ }^{9}$ Adhesions concurrent with cesarean birth are also influenced by the surgical technique. The general opinion is that adhesion incidence is within the $46-65 \%$ range, depending on the number of cesarean sections. ${ }^{10,11}$ However, Authors studied women with only one previous cesarean section. Abnormal placenta development following repeated cesarean birth is concurrent with an increased risk of placenta previa and abruptio placenta in addition to placenta accreta. The risk of placenta previa has been reported to increase by $0.28-2 \%$ in patients who have undergone at least $1 \mathrm{CS}$ in a meta analysis including 36 
studies. ${ }^{12,13}$ The incidence of placenta previa was found to be 5.2 per 1,000 births in a cohort study that included an extensive 9-year follow-up period where primiparas were included. Similarly, an increase in the need for blood transfusion was found, along with an increasing number of cesarean sections, increasing in association with placenta previa. Placenta accreta is one of the most important morbidities in repeating cesarean births. The risk is reported to be associated with the increasing number of CSs, and especially with placenta previa located on the uterine anterior wall. This contrast to the common literature may be due to the surgical techniques, suture materials, placental localization differences, or racial characteristics. Hysterectomy is another significant morbidity. It is mostly associated with placenta accreta, placenta previa, uterine atony, and uterine rupture.Peripheral organ damage (such as to the intestines and bladder), inpatient duration, need for intensive care, and surgery duration are affected by the presence of placenta accreta, dense adhesions, and hysterectomy. All these outcomes are correlated with an increasing number of cesarean births. ${ }^{14,15}$ Authors found that the rates of injuries of adjacent organs (such as the bladder and intestines), placenta previa, and infectious complications were significantly higher in repeat cesarean group than in general population who undergo vaginal delivery.

The number of births is quite high in our region. Women become pregnant again within a short time after CS due to a lack of education and information, as well related social reasons, and they do not have adequate knowledge about the potential complications. This is a common problem in many regions of the world. Providing adequate contraception training can prevent an increased number of pregnancies. On the other hand, reducing the number of primary CSs and encouraging patients and physicians to consider vaginal birth after CS is of critical importance in reducing maternal-fetal mortality and morbidity related to repeat CSs.

\section{Funding: No funding sources}

Conflict of interest: None declared

Ethical approval: The study was approved by the Institutional Ethics Committee

\section{REFERENCES}

1. MacDorman MF, Menacker F, Declercq E. Cesarean birth in the United States: epidemiology, trends, and outcomes. Clin Perinatol. 2008;35(2):293-307.

2. Hamilton BE, Martin JA, Ventura SJ. Births: preliminary data for 2007. Natl Vital Stat Rep. 2009;57(12):1-23.

3. Turkey Demographic and Health Survey (TDHS) Hacettepe Institute of Population Studies Ministry of
Health. 2008. Available at: http://www.hips.hacettepe.edu.tr/turkiyede_dogurgan lik_ureme_sagligi_yaslilik_160910.pdf.

4. Voigt M, Fröhlich CW, Hüttel C, Kranke P, Mennen $\mathrm{J}$, Boessneck $\mathrm{O}$, et al. Prophylaxis of intra- and postoperative nausea and vomiting in patients during cesarean section in spinal anesthesia. Med Sci Mon: Int Med J Experiment Clinic Res. 2013;19:993-1000.

5. Bates GW, Jr, Shomento S. Adhesion prevention in patients with multiple cesarean deliveries. Am J Obstet Gynecol. 2011;205(6):S19-24.

6. Qublan HS, Tahat Y. Multiple cesarean section. The impact on maternal and fetal outcome. Saudi Med J. 2006;27(2):210-14.

7. Ben-Ami I, Schneider D, Svirsky R, et al. Safety of late second-trimester pregnancy termination by laminaria dilatation and evacuation in patients with previous multiple cesarean sections. Am J Obstet Gynecol. 2009;201(2):154.e1-5.

8. Marshall NE, Fu R, Guise JM. Impact of multiple cesarean deliveries on maternal morbidity: a systematic review. Am J Obstet Gynecol. 2011;205(3):262.e1-8.

9. Tampakoudis P. Caesarean section rates and indications in Greece: data from a 24-year period in a teaching hospital. Clin Exp Obstet Gynecol. 2004;31(4):289-92.

10. Chigbu CO, Ezeome IV, Iloabachie GC. Cesareansection on request in a developing country. Int J Gynaecol Obstet. 2007;96(1):54-6.

11. O'dwyer V, Hogan JL, Farah N, Kennelly MM, Fitzpatrick C, Turner MJ. Maternal mortality and the rising cesarean rate. Int $\mathrm{J}$ Gynecol Obstet. 2012;116(2):162-4.

12. Fawsitt CG, Bourke J, Greene RA, Everard CM, Murphy A, Lutomski JE. At what price? A costeffectiveness analysis comparing trial of labour after previous caesarean versus elective repeat caesarean delivery. PLoS One. 2013;8(3):e58577.

13. Tulandi T, Agdi M, Zarei A, Miner L, Sikirica V. Adhesion development and morbidity after repeat cesarean delivery. Am J Obstet Gynecol. 2009;201(1):e1-6.

14. Silver RM, Landon MB, Rouse DJ, Leveno KJ, Spong CY, Thom EA, Moawad AH, Caritis SN, Harper M, Wapner RJ, Sorokin Y. Maternal morbidity associated with multiple repeat cesarean deliveries. Obstet Gynecol. 2006;107(6):1226-32.

15. Lyell DJ. Adhesions and perioperative complications of repeat cesarean delivery. Am J Obstet Gynecol. 2011;205(6):11-8.

Cite this article as: Ganiga P, Rudrappa S. A prospective study of maternal and fetal outcome in repeat LSCS mother. Int J Reprod Contracept Obstet Gynecol 2019;8:1327-30. 